\title{
EL EJERCICIO DE LOS DERECHOS LINGÜÍSTICOS DE LOS PUEBLOS INDÍGENAS U ORIGINARIOS EN EL PERÚ
}

\section{THE EXERCISE OF THE LINGUISTIC RIGHTS OF INDIGENOUS PEOPLES IN PERU}

\author{
RIMAYKUNAQ ALLANKAYKUNA RUWAY KAYNINQA \\ QESWARUNA LLAQTANKUNAMANTA PERU JATUN LLAQTA \\ PAQAREQKUNAMANTA(1)
}

\author{
Antonio Eliseo Huañahui Sillocca ${ }^{(2)}$ \\ Universidad Nacional de San Antonio Abad del Cusco
}

\begin{abstract}
Resumen: Este artículo trata sobre los derechos lingüísticos de los pueblos originarios en el acceso a la administración de justicia. Usar las lenguas indígenas en forma individual y colectiva es un derecho que el Estado tiene la obligación de reconocer, respetar, proteger y promover. Los idiomas originarios deben ser garantizados, fomentados y fortalecidos, sin embargo, en Perú la cultura occidental aún subordina a los pueblos indígenas. Dicha práctica de dominación es percibida como un hecho "normal" que ha logrado interiorizarse en la población indígena, generando un problema de autoestima. Es necesario construir un nuevo modelo de Estado con instituciones y una justicia pluriculturales y multilingües.
\end{abstract}

Palabras clave: Derechos lingüísticos, lengua indígena, plurilingüismo, multilingüismo, acceso a la justicia, barreras lingüísticas.

\begin{abstract}
This article deals with the linguistic rights of indigenous peoples in access to the administration of justice. Using indigenous languages individually and collectively is a right that the State has the obligation to recognize, respect, protect and promote. The original languages must be guaranteed, promoted and strengthened, however, in Peru the western culture still subordinates the

(1) Traducción. Adrian T. Valer Delgado. Quechua / Cusco Qollao

(2) Abogado por la Universidad Nacional de San Antonio Abad del Cusco, con estudios de Post Grado: Maestría en Derecho Constitucional y Doctorado en Derecho (Egresado), Profesor Universitario en la Especialidad de Constitución y Derechos Humanos en la Tricentenaria Universidad Nacional de San Antonio Abad del Cusco - UNSAAC. Correo electrónico: husianel@hotmail.com
\end{abstract}


indigenous peoples. This practice of domination is perceived as a "normal" fact that has been internalized in the indigenous population, generating a problem of selfesteem. It is necessary to build a new model of the State with multicultural and multilingual institutions and justice.

Key words: Linguistic rights, indigenous language, plurilingualism, multilingualism, access to justice, language barriers.

Ñujñu: Kay qelqasqa riman rimaykuna allankayninmanta paqareq llaqtakunaq kuskachay kamachicuyman jaykunankupaq juj runallapaq jinaspapas aylluntimpaq rimay qallukunaq allankayniy kamachiq umalleqpaq ruwananmi reqsenampaq, jaynimqanampaq, amachaynanpaq jinaspapas astawan kanampaq. Paqaremoq rimaykunaqa allinkawsanampaq, astawan wiñananpaq, kallpachakunampaq, ichaka, Peru Jatunllaqta, intiqchinkanan yachay Ilaqtakunamantaqa saruchankunkuraqmi paqareq runa llaqtakunataqa, chay saruchakuy camachicuy ruwaymi "allimpas kanmanjina" jaykun paqareq runakunaman, manapas pay kikinkuta munakunmanchu jina. Chaymi juj mosoq juj jatun kamachikuq Estado nisqata ruwana kanman jinaspapas aska yachaykunamanta jinaspapas aswan rimaykunamanta.

Kichana simikuna: Derechos lingüísticos, lengua indígena, plurilingüismo, multilingüismo, acceso a la justicia, barreras lingüísticas 


\section{Introducción}

En el Perú, a inicios y a fines de la Colonia, se establecieron políticas monolingües, esta situación continuó durante toda la República. En efecto, en el Perú actual todavía la cultura occidental domina diferentes ámbitos de la vida social y frente a ello las demás culturas parecen subordinadas.

Recién en la década de los 70, con el gobierno de Velasco Alvarado se oficializa el quechua. Luego, con los instrumentos jurídicos internacionales, con los cambios constitucionales en Latinoamérica, y en el Perú con la Constitución de 1993, tanto en el artículo 2 , inc. 19 y en el artículo 48, en los cuales se señala que nadie debe ser discriminado por motivo de "idioma", así como se oficializa a todas las lenguas donde mayoritariamente son habladas, y recientemente con la Ley 29735 de 2011, se regula el uso, preservación, desarrollo, recuperación, fomento y difusión de las lenguas indígenas u originarias. De esta manera se plantea un gran reto al Estado: brindar los servicios de educación, salud, justicia, identificación, entre otros, en las lenguas originarias en las localidades donde estas son habladas mayoritariamente.

Según datos oficiales del Ministerio de Cultura, existen 55 pueblos originarios en el Perú y se hablan 48 las lenguas originarias de las cuales 44 son amazónicas y 4 andinas, todas ellas agrupadas en 19 familias lingüísticas que constituyen medios de comunicación de dichos pueblos indígenas u originarios. Estos pueblos originarios afrontan problemas públicos identificados como no poder ejercer plenamente sus derechos lingüísticos, en vista de que la administración pública y los prestadores de servicios públicos funcionan bajo la lógica de un Estado monolingüe y monocultural, así como actos de discriminación por el uso de sus lenguas, el desprestigio y desvaloración y el abandono de ellas, junto a otros elementos que los identifican culturalmente. Por lo general, el uso oral y escrito de las lenguas originarias suele limitarse al ámbito doméstico y comunitario.

La importancia para los pueblos indígenas u originarios de acceder a la justicia en su propio idioma radica en garantizarles un mecanismo de atención a sus conflictos jurídicos, para permitir la optimización de sus demás derechos fundamentales como el derecho a la igualdad, identidad o libre desarrollo de la personalidad.

\section{Lenguas indígenas u originarias en el Perú}

Según el artículo 3, numeral 14 del reglamento de la Ley 29735, se entiende por lenguas indígenas u originarias del Perú, a todas aquellas que son anteriores a la difusión del idioma castellano o español y que se preservan o emplean en el ámbito del territorio nacional. En conjunto, todas estas lenguas representan la expresión de una identidad colectiva, así como una manera de distinta de entender y describir la realidad. 
Durante muchos siglos, las lenguas indígenas $\mathrm{u}$ originarias han sido consideradas como "dialectos", es decir, como variantes de una lengua, tratándolas como lenguas inferiores al castellano. De la misma forma, se creía que las lenguas indígenas u originarias en el Perú no tenían gramática. Sin embargo, a través de varias investigaciones, en las últimas décadas se ha logrado clasificarlas en familias lingüísticas.

Como mencionamos, en el Perú existen 48 lenguas originarias: 44 amazónicas y 4 andinas, las cuales están agrupadas en 19 familias lingüísticas y constituyen medios de comunicación de 55 pueblos indígenas u originarios. De acuerdo con los datos del Censo Nacional de Población y Vivienda (2007), 4'045,713 personas tienen por lengua materna una lengua indígena $u$ originaria, esto equivale al 15\% de la población nacional. Para ilustrar mostramos los siguientes cuadros:

TABLA 1: Distribución de las personas que declararon una lengua indígena como lengua materna

\begin{tabular}{|l|c|c|}
\hline \multicolumn{1}{|c|}{ Lengua } & Número de habitantes & Porcentaje \\
\hline Quechua & $3^{\prime} 360,331$ & $83.06 \%$ \\
\hline Aimara & 443,248 & $10.96 \%$ \\
\hline Ashaninka & 67,724 & $1.67 \%$ \\
\hline Otra lengua nativa & 174,410 & $4.31 \%$ \\
\hline Total general & $4^{\prime} 045,713$ & $100 \%$ \\
\hline
\end{tabular}

Fuente: Dirección de Lenguas Indígenas del Ministerio de Cultura a partir de datos del Censo Nacional de Población y Vivienda de 2007.

TABLA 2: Provincias con alta proporción de personas que declararon una lengua indígena como lengua materna

\begin{tabular}{|l|l|c|}
\hline \multicolumn{1}{|c|}{ Región } & \multicolumn{1}{c|}{ Provincia } & Hablantes de lenguas indígenas \\
\hline Amazonas & Condorcanqui & $91 \%$ \\
\hline Ancash & Carlos Fermín Fitzcarrald & $91 \%$ \\
\hline Ancash & Mariscal Luzuriaga & $91 \%$ \\
\hline Ancash & Pomabamba & $85 \%$ \\
\hline Apurímac & Cotabambas & $90 \%$ \\
\hline Apurímac & Chincheros & $81 \%$ \\
\hline Ayacucho & Cangallo & $90 \%$ \\
\hline Ayacucho & Víctor Fajardo & $86 \%$ \\
\hline Ayacucho & Vilcashuamán & $90 \%$ \\
\hline Cusco & Acomayo & $88 \%$ \\
\hline Cusco & Canas & $92 \%$ \\
\hline Cusco & Chumbivilcas & $91 \%$ \\
\hline
\end{tabular}




\begin{tabular}{|l|l|c|}
\hline Cusco & Paruro & $92 \%$ \\
\hline Cusco & Paucartambo & $86 \%$ \\
\hline Huancavelica & Acobamba & $86 \%$ \\
\hline Puno & Carabaya & $85 \%$ \\
\hline Puno & Moho & $86 \%$ \\
\hline Ucayali & Purús & $69 \%$ \\
\hline
\end{tabular}

Fuente: Dirección de Lenguas Indígenas del Ministerio de Cultura a partir de datos del Censo Nacional de Población y Vivienda de 2007.

TABLA 3: Lista de las 10 regiones con mayor porcentaje de habitantes de lengua indígena

\begin{tabular}{|l|c|c|c|c|c|}
\hline \multicolumn{1}{|c|}{ Región } & Quechua & Aimara & Asháninka & Otra lengua indígena & Total \\
\hline Apurímac & $70.68 \%$ & $0.18 \%$ & $0.02 \%$ & $0.03 \%$ & $70.91 \%$ \\
\hline Puno & $38.04 \%$ & $27.02 \%$ & $0.05 \%$ & $0.03 \%$ & $65.14 \%$ \\
\hline Huancavelica & $64.06 \%$ & $0.09 \%$ & $0.02 \%$ & $0.02 \%$ & $64.19 \%$ \\
\hline Ayacucho & $63.35 \%$ & $0.13 \%$ & $0.05 \%$ & $0.06 \%$ & $63.59 \%$ \\
\hline Cusco & $51.86 \%$ & $0.18 \%$ & $0.27 \%$ & $0.91 \%$ & $53.22 \%$ \\
\hline Ancash & $31.51 \%$ & $0.05 \%$ & $0.01 \%$ & $0.06 \%$ & $31.63 \%$ \\
\hline Huánuco & $28.56 \%$ & $0.08 \%$ & $0.10 \%$ & $0.14 \%$ & $28.88 \%$ \\
\hline Moquegua & $9.58 \%$ & $10.52 \%$ & $0.03 \%$ & $0.18 \%$ & $20.41 \%$ \\
\hline Tacna & $2.39 \%$ & $16.27 \%$ & $0.03 \%$ & $0.10 \%$ & $18.79 \%$ \\
\hline Madre de Dios & $15.62 \%$ & $0.94 \%$ & $0.03 \%$ & $2.20 \%$ & $18.79 \%$ \\
\hline
\end{tabular}

Fuente: Dirección de Lenguas Indígenas del Ministerio de Cultura a partir de datos del Censo Nacional de Población y Vivienda de 2007.

\subsection{Pluriculturalidad, multiculturalidad e interculturalidad}

En principio debemos definir estos tres conceptos claves: multiculturalidad, pluriculturalidad e interculturalidad, que se refieren a la diversidad cultural de una sociedad, que, sin embargo, apuntan a distintas maneras de conceptualizar esa diversidad y a desarrollar prácticas relacionadas con la diversidad en la sociedad y sus instituciones.

Al respecto, tenemos los conceptos desarrollados por María del Mar Bernabé Villodre (2012) de la Universidad de Valencia(3) y que a continuación señalamos:

Sobre el concepto de pluriculturalidad, dicha autora señala que el prefijo "pluri-" hace referencia a "muchos", es decir, con él se puede hacer referencia a muchas culturas, a una pluralidad de culturas, agrega que desde el punto de vista sociológico, el término pluralidad designa la presencia de diversas tendencias

(3) BERNABÉ VILLODRE, María del Mar. Pluriculturalidad, Multiculturalidad e Interculturalidad. Aportaciones Arbitradas - Revisita Educativa Hekademos, 11, Año V, Junio 2012. Pág. 69 y 70. 
ideológicas y grupos sociales coordinados en una unidad estatal, por lo que para esta autora la pluriculturalidad puede ser entendida como la "presencia simultánea de dos o más culturas en un territorio y su posible interrelación".

En cuanto a la multiculturalidad, señala que "multi-" hace referencia a una cierta cantidad de elementos, por lo que la multiculturalidad se puede definir como "la presencia en un territorio de diferentes culturas que se limitan a coexistir pero no a convivir" y en resumen "una situación multicultural supone la existencia de muchas culturas unidas en lo espacial pero no en lo social." (p. 9).

La interculturalidad, la considera como una meta necesaria y el prefijo "inter-" se refiere a "entre culturas", es decir entre las diferentes culturas que habitan un mismo territorio. Entonces la interculturalidad no es un concepto cerrado ni excluyente, en vista de que promueve la comunicación entre diferentes culturas, el encuentro cultural para contrastar y aprender mutuamente la toma de conciencia de la diferencia para resolver conflictos, y el reconocimiento y aceptación de la diferencia, lo que lleva al establecimiento de relaciones culturales y por ende a una integración de culturas, donde las sociedades democráticas fomenten el encuentro y la comprensión entre las diversas culturas de un territorio. Como se puede ver la interculturalidad aboga por la defensa de la diversidad, del respeto y del diálogo cultural. La interculturalidad implica finalmente el reconocimiento y la comprensión de la existencia de otras culturas, además de respeto, comunicación e interacción. Una sociedad será intercultural cuando sus miembros interactúen y se enriquezcan con esa interacción.

Según el Ministerio de Cultura, la interculturalidad puede definirse como un "proceso deintercambio, diálogoy aprendizajequebuscagenerarrelaciones deequidadentre diversos grupos étnico-culturales que comparten un espacio, a partir del reconocimiento y valoración positiva de sus diferencias culturales." (MINISTERIO DE CULTURA,2016. p.9)

En resumen, la interculturalidad es una práctica de respeto y valoración de nuestras diferencias, la interacción armónica entre dos o más culturas de un modo horizontal y sinérgico con respeto mutuo y considerando a todos los grupos por igual. La interculturalidad es la interacción entre culturas, como un proceso de comunicación entre diferentes grupos humanos, con diferentes costumbres, siendo la característica fundamental "la horizontalidad", es decir, ningún grupo cultural está por encima del otro, por el contrario, se promueve la igualdad, integración y convivencia armónica entre ellas.

\subsection{Plurilingüismo y multilingüismo}

Ambas terminologías aparentemente guardan diferencias y a la vez similitudes y relaciones. Para mayor comprensión es necesario diferenciar ambos 
términos. En efecto, de manera general el plurilingüismo se refiere a la capacidad y habilidad de aprender otro idioma; mientras que el multilingüismo es la utilización de varios idiomas en igualdad de condiciones, es un medio de preservación de la cultura.

Según María Esther Moreno García, "el plurilingüismo se define como las variedades lingüísticas que utiliza un mismo locutor incluyendo la materna como primera y las posteriormente adquiridas (...) el plurilingüismo tiene que contemplarse en el contexto del pluriculturalismo". La lengua no es solo un aspecto importante de la cultura, sino también un medio de acceso a las manifestaciones culturales. Por otra parte, considera al multilingüismo como el conocimiento de varias lenguas o la coexistencia de distintas lenguas en una sociedad determinada, es decir, la convivencia de numerosas variedades lingüísticas en un área geográfica determinada (MORENO GARCÍA, p 120).

\section{Los derechos lingüísticos: el derecho de usar el propio idioma indígena}

En la legislación, en materia de derechos lingüísticos de los pueblos indígenas u originarios existen instrumentos jurídicos a nivel internacional y a nivel nacional.

\subsection{En el plano internacional}

Los gobiernos y organismos internacionales han mostrado su preocupación e interés para evitar la extinción o desaparición de las lenguas indígenas a nivel mundial y por ende combatir la violación de los derechos lingüísticos de los pueblos indígenas u originarios; por lo que a nivel internacional se han desarrollado muchos instrumentos jurídicos supranacionales en los cuales se establecen obligaciones para los Estados en materia de derechos lingüísticos.

a. El Convenio 169 de la OIT sobre Pueblos Indígenas y Tribales en Países Independientes, ratificado por el Perú el 2 de diciembre de 1993 mediante Resolución Legislativa 26253, instrumento legal por el que el Estado peruano se obliga a preservar las lenguas indígenas y promover el desarrollo y la práctica de las mismas.

"Artículo 28, 3. Deberán adoptarse disposiciones para preservar las lenguas indígenas de los pueblos interesados y promover el desarrollo y la práctica de las mismas."

b. La Declaración de las Naciones Unidas sobre los Derechos de los Pueblos Indígenas, aprobada por la Asamblea General mediante Resolución del 13 de setiembre de 2007. Establece que los hablantes 
en lenguas originarias tienen el derecho de preservar sus propias lenguas y utilizarlas en cualquier actuación de carácter público y para ello el Estado debe adoptar las medidas necesarias.

"Artículo 13, 1. Los pueblos indígenas tienen derecho a revitalizar, utilizar, fomentar y transmitir a las generaciones futuras sus historias, idiomas, tradiciones orales, filosofías, sistemas de escritura y literaturas, y a atribuir nombres a sus comunidades, lugares y personas y mantenerlos.

Artículo 13, 2. Los Estados adoptarán medidas eficaces para garantizar la protección de ese derecho y también para asegurar que los pueblos indígenas puedan entender y hacerse entender en las actuaciones políticas, judiciales y administrativas, proporcionando para ello, cuando sea necesario, servicios de interpretación u otros medios adecuados.

Artículo 16, 1. Los pueblos indígenas tienen derecho a establecer sus propios medios de información en sus propios idiomas y a acceder a todos los demás medios de información no indígenas sin discriminación alguna."

c. La Declaración Americana de los Derechos de los Pueblos Indígenas, aprobada el 14 de junio de 2016, establece que:

"Artículo II. Los estados reconocen y respetan el carácter pluricultural y multilingüe de los pueblos indígenas, quiénes forman parte integral de sus sociedades.

Artículo XIV. Sistemas de conocimientos, lenguaje y comunicación.

4. Los Estados, en conjunto con los pueblos indígenas, realizarán esfuerzos para que dichos pueblos puedan comprender y hacerse comprender en sus propias lenguas en procesos administrativos, políticos y judiciales, facilitándoles, si fuera necesario, intérpretes u otros medios eficaces.

Artículo XXII. Derecho y jurisdicción indígena

3. Los asuntos referidos a personas indígenas o a sus derechos o intereses en la jurisdicción de cada Estado, serán conducidos de manera tal de proveer el derecho a los indígenas de plena representación con dignidad e igualdad ante la ley. En consecuencia, tienen derecho sin discriminación, a igual protección y beneficio de la ley, incluso, al uso de intérpretes lingüísticos y culturales." 
d. La Declaración Universal de Derechos Lingüísticos (Barcelona, junio de 1996):

"Artículo 18, 1. Toda comunidad lingüística tiene derecho a que las leyes y otras disposiciones jurídicas que le conciernan se publiquen en la lengua propia del territorio.

Artículo 20, 1. Todo el mundo tiene derecho a usar de palabra y por escrito, en los Tribunales de Justicia, la lengua históricamente hablada en el territorio donde están ubicadas. Los Tribunales deben utilizar la lengua propia del territorio en sus actuaciones internas y, si por razón de la organización judicial del Estado, el procedimiento se sigue fuera del lugar de origen hay que mantener la lengua de origen.

2. Con todo, todo el mundo tiene derecho a serjuzgado en una lengua que le sea comprensible y pueda hablar, o a obtener gratuitamente un intérprete."

e. La Convención para la Salvaguardia del Patrimonio Cultural Inmaterial, ratificada por D. S. 047-2006-RE, que considera las tradiciones y expresiones orales como una de las manifestaciones del patrimonio cultural de carácter inmaterial, incluido el idioma como vehículo de dicho patrimonio.

f. El Convenio Marco para la Protección de las Minorías Nacionales 157 del Consejo de Europa del 23 de enero de 1998, en el cual se establece que no solo se debe respetar la identidad étnica, cultural, lingüística y otros, sino también crear las condiciones apropiadas que permitan expresar, preservar y desarrollar esa identidad, así como el "derecho a utilizar libremente y sin trabas su lengua minoritaria tanto en privado como en público, oralmente y por escrito".

g. Otras normas internacionales directamente relacionadas con la protección de los derechos lingüísticos de los habitantes de lenguas indígenas u originarias que sirven de soporte para el presente trabajo son: la Declaración Universal de Derechos Humanos; el Pacto de Derechos Civiles y Políticos; el Pacto de Derechos Sociales, Económicos y Culturales; la Declaración para la Eliminación de todas las Formas de Discriminación; la Declaración Americana de Derechos y Deberes del Hombre y la Convención Americana sobre Derechos Humanos.

\subsection{En el plano nacional}

Se cuenta con un marco legal que protege los derechos lingüísticos de los pueblos indígenas. 


\section{a. Constitución Política del Perú de 1993}

"Artículo 2, 19. Toda Persona tiene derecho: A su identidad étnica y cultural. El Estado reconoce y protege."

Artículo 17. (Último párrafo). El Estado garantiza la erradicación del analfabetismo. Asimismo fomenta la educación bilingüe e intercultural, según las características de cada zona. Preserva las diversas manifestaciones culturales y lingüísticas del país. Promueve la integración nacional.

Artículo 48. Son idiomas oficiales el castellano y, en las zonas donde predominen, también lo son el quechua, el aimara y las demás lenguas aborígenes, según la ley."

En cuanto a la regulación legislativa, la Ley 27811, de Protección de la Diversidad Biológica y de los Conocimientos Colectivos de los Pueblos Indígenas, señala que son pueblos originarios aquellos "que tienen derechos anteriores a la formación del Estado peruano, mantienen una cultura propia, un espacio territorial y se autoreconocen como tales."

b. Ley 29565, de Creación del Ministerio de Cultura y el Decreto Supremo 005-2013-MC, que aprueba el Reglamento de Organización y Funciones del Ministerio de Cultura.

c. Ley 29735, que regula el Uso, Preservación, Desarrollo, Recuperación, Fomento y Difusión de las Lenguas Originarias del Perú. En su artículo 1 establece que las lenguas indígenas u originarias "son la expresión de una identidad colectiva y de una manera distinta de concebir y de describir la realidad, por tanto, gozan de las condiciones necesarias para su mantenimiento y desarrollo en todas las funciones." Asimismo, reconoce el derecho de toda persona a usar su lengua indígena u originaria en los ámbitos público y privado, a ser atendida en su lengua materna en los organismos o instancias estatales, y a gozar y disponer de los medios de traducción directa o inversa que garanticen el ejercicio de sus derechos en todo ámbito. Esta ley fue reglamentada por el D. S. 004-2016-MC.

d. Ley 29785, del Derecho a la Consulta Previa a los Pueblos Indígenas Originarios, reconocido en el Convenio 169 de la Organización Internacional del Trabajo (OIT) y su Reglamento D. S. 001-2012.MC.

e. Decreto Legislativo 1342, que promueve la transparencia y el derecho de acceso de la ciudadanía al contenido de las decisiones jurisdiccionales, cuya norma, entre otros temas trata sobre el lenguaje y acceso a la justicia. 
"Artículo 4.- Lenguaje y acceso a la justicia

4.1. Las instituciones del sistema de justicia tienen el deber de atender y emitir sus decisiones en el idioma en el que se expresa originariamente la persona usuaria del servicio. En las localidades en las que la población mayoritaria hable una lengua originaria, los puestos para cubrir las plazas de Juzgados, Fiscalías y la Policía Nacional del Perú, así como el personal administrativo que labora en las instituciones de la administración de justicia deben preferentemente, ser ocupadas por personas que conocen y pueden comunicarse en el idioma de la población de la localidad.

4.2. Los operadores del sistema de justicia evitarán usar términos en latín o cualquier otro arcaísmo que dificulte la comprensión de las expresiones y términos legales que contiene sus actos o resoluciones."

f. Otras normas reglamentarias que regulan las lenguas originarias de los pueblos indígenas. El D. S. 027-2007-PCM que define y establece las políticas nacionales de obligatorio cumplimiento para las entidades del gobierno nacional. El D.S. 003-2015-MC, que aprueba la política nacional para la transversalización del enfoque intercultural. La Resolución Administrativa 142-2016-CE-PJ, que aprueba documento denominado "Mapa Etnolingüístico Judicial". La Resolución Administrativa 200-2016-CE-PJ, que aprueba el "Protocolo de Justicia de Paz Escolar". La Resolución Ministerial 427-2016-MC, que aprueba el Plan Estratégico Sectorial Multianual (PESEM) 2017-2021 del Sector Cultura. El D.S. 005-2017.MC, que aprueba la Política Nacional de Lenguas Originarias, Tradición Oral e Interculturalidad; y el D.S. 011-2018-MINEDU que aprueba el Mapa Etnolingüístico del Perú.

\section{Los derechos lingüísticos como derechos humanos}

Los derechos lingüísticos de los pueblos indígenas no son creados por el Estado, son reconocidos, por ser su práctica y su ejercicio, preexistentes al Estado mismo.

Los derechos lingüísticos, considerados como derechos humanos reconocidos en nuestro marco normativo vigente, sirven de guía para las acciones que el Estado debe realizar en aras de su garantía y protección.

Para poder ubicar los derechos lingüísticos dentro de los derechos humanos, se debe tomar en cuenta que el lenguaje cumple dos funciones, una de expresión y otra de comunicación. Como medio de expresión, es decir, como el derecho a hablar, el derecho al lenguaje forma parte de los derechos humanos fundamentales y está dentro del catálogo de los derechos humanos de primera generación, al igual que los otros derechos como: la libertad de conciencia, 
religión, creencia u opinión, en vista de que estos derechos se consideran atributos naturales o inherentes de todo individuo.

De las normas supranacionales, y de las normas en el plano nacional, se desprende que existe un imperativo de respetar, proteger y promover el uso real, efectivo, concreto y material de los idiomas indígenas que obliga al Estado peruano a que, a través de sus organismos o instituciones de diferentes niveles, promueva un modelo de justicia multilingüe. Las instituciones del sistema de justicia tienen el deber de atender y emitir sus decisiones en el idioma en el que se expresa originariamente la persona usuaria del servicio, lo cual amerita la institucionalización del multilingüismo en la justicia, implementando la aplicación y la puesta en práctica de la normas existentes, diseñando los sistema de organización, destinando los recursos humanos y materiales necesarios, la difusión de las normas entre los usuarios y la práctica real de una cultura jurídica en los operadores de la justicia peruana.

Raquel Yrigoyen Fajardo (2003, p. 77), señala que:

"En síntesis, el derecho de usar los idiomas indígenas supone la atribución de los pueblos indígenas y de las minorías lingüísticas, así como de sus miembros, de utilizar dichos idiomas, y que su uso reciba protección y promoción en el marco de su propia identidad cultural. De su parte, el Estado está obligado a respetar, proteger y promover el uso y desarrollo de los idiomas indígenas, así como la identidad cultural de dichos pueblos y sus miembros."

De ello se desprende que los derechos lingüísticos son derechos fundamentales que están ubicados dentro de los derechos de primera generación en el marco de los derechos humanos que reconocen la libertad de todas las personas a usar su propia lengua o idioma materno en todos los espacios sociales, en forma individual o colectiva. Ello implica el desarrollo de su vida personal, social, educativa, política y profesional en su propia lengua, así como recibir atención de los organismos públicos y pertenecer a una comunidad lingüística reconocida y respetada. El respeto de los derechos lingüísticos permite a los hablantes de lenguas indígenas u originarias, cuando se materializa, el acceso real y efectivo a los derechos y servicios públicos esenciales como una adecuada atención de salud, servicios educativos, un proceso judicial justo, acceso a la información, etc.

El Reglamento de la Ley 29735, que regula el Uso, Preservación, Desarrollo, Recuperación, Fomento y Difusión de las Lenguas Originarias del Perú, señala como derechos lingüísticos, los siguientes:

1. Usar la lengua indígena u originaria en forma oral y escrita en cualquier espacio público o privado. 
2. Ser atendido/a y recibir información oral, escrita o audiovisual en su lengua indígena u originaria en las entidades públicas y privadas que prestan servicios públicos.

3. Recibir educación en su lengua indígena u originaria en forma oral y escrita en todos los niveles de educación.

4. Identificarse, registrarse y ser reconocido/a ante los demás con su propio nombre en la lengua indígena u originaria.

5. Usar el nombre de la lengua indígena u originaria reconocida por el pueblo indígena u originario que la habla.

6. Acceder a los medios y recursos para el adecuado aprendizaje de la lengua o las lenguas indígenas u originarias en el ámbito nacional.

7. Recuperar, usar y mantener topónimos en lengua indígena u originaria referidos a comunidades y lugares en el ámbito nacional, regional, departamental y local.

8. Recuperar y utilizar terminología propia de las lenguas indígenas $\mathrm{u}$ originarias principalmente en el ámbito artístico, académico, medicinal, musical y espiritual.

9. Obtener, almacenar y difundir las investigaciones lingüísticas y culturales relativas a sus pueblos indígenas u originarios y sus lenguas.

10. Contar con la presencia de la lengua y la cultura de los pueblos indígenas $u$ originarios en los medios de comunicación estatal de ámbito nacional, regional, departamentaly local, según predominancia.

De los derechos antes señalados, el derecho a los idiomas indígenas constituye un derecho en sí mismo, con su propio contenido esencial y constituye parte del derecho a la propia identidad cultural reconocida por el inciso 19 del artículo 2, concordante con el artículo 17 de la Constitución Política del Perú (1993), y en ello el idioma deviene en un eje central de la cultura. Dentro de este marco el Estado peruano debe asumir como obligaciones: a) No impedir, privar o limitar el uso de los idiomas indígenas; b) Respetar y garantizar el uso real y efectivo de los idiomas indígenas en las instancias oficiales, en la difusión de las disposiciones legales, en las instancias judiciales, los servicios municipales y en los sistemas registrales en todo sistema administrativo del Estado; c) Reconocer los idiomas indígenas; d) Preservar, proteger o conserva los idiomas indígenas y su uso; y e) Promover el uso y desarrollo de los idiomas mediante políticas públicas en todas las esferas de la vida social.

La Constitución Política del Perú (1993), en el inciso 14 del artículo 139, señala el derecho de defensa y otras garantías como los principios judiciales o el debido proceso, como de cumplimiento obligatorio dentro de la administración de justicia para las personas inculpadas por la comisión de un delito, quienes tienen derecho no solo a ser asistidos gratuitamente por un intérprete o traductor si no 
comprenden o no hablan el idioma del Juzgado o Tribunal, sino también a ser escuchadas y entendidas en el sentido real de su versión de defensa por el juzgador.

Las instituciones del sistema de justicia tienen el deber de atender, escuchar y emitir sus decisiones en el idioma en el que se expresa originariamente la persona usuaria del servicio y para ello en las localidade,s en las que la población mayoritaria hable una lengua originaria, los puestos para cubrir las plazas de Juzgados, Fiscalías y la Policía Nacional del Perú, así como el personal administrativo que labora en las instituciones de la administración de justicia deben, preferentemente, ser ocupadas por personas que conozcan y puedan comunicarse en el idioma de la población de la localidad. También los operadores del sistema de justicia deben evitar usar términos en latín o cualquier otro arcaísmo que dificulte la comprensión de las expresiones y términos legales que contienen sus actos o resoluciones, todo ello está relacionado al derecho al juez natural que estos pueblos indígenas tienen.

Sobre el ejercicio del derecho de defensa, el debido proceso y el derecho a la identidad cultural, el Tribunal Constitucional señala que:

"no sería posible si, en el seno del proceso, no se hubiera nombrado intérprete al recurrente teniendo este como idioma propio uno distinto al castellano y, en consecuencia, no tuviera la posibilidad de entender el idioma usado en los tribunales, a fin de ejercer su derecho de defensa constitucionalmente protegido. Entonces el derecho de defensa es irrealizable si no se cuenta con un intérprete o traductor, vulnerándose con ello, además, los derechos fundamentales al debido proceso y a la identidad cultural." (Exp. 4719-2007-PHC/TC, párr. 1 y 17)

\subsection{El carácter individual y colectivo de los derechos lingüísticos}

El profesor de la Universidad Autónoma Metropolitana Unidad - Iztapalapa de México, Enrique Hamel, señala que

"Los derechos lingüísticos forman parte de los derechos humanos fundamentales, tanto individuales como colectivos, y se sustentan en los principios universales de la dignidad de los humanos y de la igualdad formal de todas las lenguas." Continúa señalando que "En un nivel individual significan el derecho de cada persona a identificarse de manera positiva con su lengua materna, y que esta identificación sea respetada por los demás" (ENRIQUE HAMEL, p. 12).

Esto implica, como derechos fundamentales, el derecho de cada individuo a aprender y desarrollar libremente su propia lengua materna, a recibir educación 
pública a través de ella, a usarla en contextos oficiales socialmente relevantes, y a aprender por lo menos una de las lenguas oficiales de su país de residencia. Concluye este profesor señalando que en el nivel de las comunidades lingüísticas los derechos lingüísticos comprenden el derecho colectivo de mantener su identidad y alteridad etnolingüísticas.

La lengua propia de los pueblos indígenas u originarios es el principal medio por el que las poblaciones indígenas manifiestan su cultura y por tanto tiene vital importancia en el proceso de reproducción cultural, de tal manera que la lengua es parte fundamental de la cultura, le es propia y necesaria para la supervivencia del grupo como tal, por lo tanto, el derecho al uso de la lengua es un derecho que se funda en el derecho a la libertad de expresión, por el derecho a la dignidad y a la identidad, derechos que están reconocidos por los instrumentos jurídicos de nivel internacional y regional, y en el Perú están reconocidos por el inciso 19 del artículo 2, concordante con los artículos 17 y 48 de la Constitución Política (1993), así como por las leyes sobre la materia y sus reglamentos.

\section{Política nacional y exclusión en el ejercicio de los derechos lingüísticos indígenas u originarios en el Perú}

El Estado peruano desde su fundación conserva de la Colonia la conducta de negar la diversidad impuesta como una ideología, manteniendo al castellano como un referente lingüístico único y esta perspectiva es la que hasta ahora forma parte del imaginario colectivo, de esta manera las posibilidades de desarrollar políticas de Estado que apuesten por la preservación o el desarrollo real y efectivo de las lenguas indígenas peruanas han sido históricamente imposibles.

Recién en el año 1975, mediante el Decreto Ley 21156, el gobierno del general Juan Velasco Alvarado por primera vez reconoce el quechua, al igual que el castellano, como lenguas oficiales de la República Peruana, disponiendo la enseñanza del quechua de forma obligatoria en todos los niveles de educación. También estableció que a partir del año 1977 las acciones judiciales en las cuales las partes sean sólo quechua hablantes, se realicen en este idioma. Posteriormente, años después la Constitución de 1979 fue la primera que posibilitó que otros idiomas distintos al castellano fueran declarados oficiales:

"Artículo 83. El castellano es el idioma oficial de la República. También son de uso oficial el quechua y el aimara en las zonas y la forma que la ley establece. Las demás lenguas aborígenes integran asimismo el patrimonio cultural de la nación."

Finalmente, la Constitución de 1993, estableció que además del castellano, los idiomas indígenas también son oficiales: 
"Artículo 48. Son idiomas oficiales el castellano y, en las zonas donde predominen, también lo son el quechua, el aimara y las demás lenguas aborígenes, según la ley."

Pero a pesar de los reconocimientos constitucionales de los derechos lingüísticos y otros derechos de los pueblos indígenas u originarios, conforme señala Wilfredo Ardito Vega:

"En el Perú actual, la cultura occidental domina múltiples ámbitos de la vida social, económica, sistema político, educación, sistema jurídico, religión e inclusive la misma concepción de la belleza, frente a la cual, las demás culturas parecen subordinadas, aunque dentro de los sectores intelectuales subsisten posturas teocéntricas... La dominación es percibida como un hecho natural o normal y se asume que las cosas deben ser necesariamente de este modo, de esta manera se ha interiorizado la dominación. Aunque se admita que vivimos en un país multicultural y pluriétnico, esto no implica el reconocimiento de relaciones de equidad entre los diversos pueblos que habitan el Perú ... la existencia de culturas y pueblos indígenas suele ser considerada un problema serio para el desarrollo y la prosperidad del país, o aún su viabilidad" (ARDITO VEGA, p. 9).

Recientemente el Estado peruano aprobó la Política Nacional de Lenguas Originarias, Tradición Oral e Interculturalidad, en la que reconoce que los sistemas comunicativos usados por los pueblos indígenas u originarios son lenguas o idiomas en el pleno sentido de sus términos, tal como lo es el castellano.

Hay algunos avances en el ámbito nacional, tales como la institucionalización del Registro Civil Bilingüe en el RENIEC, la Educación Intercultural Bilingüe en el sector educación, la creación de la Dirección de Desplazados y Cultura de Paz del Ministerio de la Mujer y Poblaciones Vulnerables, el noticiero en quechua "Nuqanchik" de TV Perú y Radio Nacional del Perú, la creación del Instituto Nacional de Investigaciones de la Amazonía Peruana en el Ministerio del Ambiente, el Centro de Asuntos Interculturales, Comunidades y Rondas Campesinas CAIMP del Ministerio Público, la Oficina Nacional de Justicia de Paz y Justicia Indígenas ONAJUP del Poder Judicial y el Programa de Pueblos Indígenas de la Adjuntía de Medio Ambiente, Servicios Públicos y Pueblos Indígenas en la Defensoría del Pueblo. Sin embargo, todos estos esfuerzos no son suficientes para la implementación de una política nacional integral en todos los sectores u organismos estatales. 


\subsection{Enfoques transversales de la política nacional de lenguas originarias}

Como enfoque para una política nacional de promoción de las lenguas originarias podemos señalar entre otros:

- el enfoque intercultural, mediante el reconocimiento de las diferencias culturales como uno de los pilares de la construcción de una sociedad democrática; el enfoque de derechos humanos, mediante su promoción y protección señalando aquellos que han sido vulnerados, así como identificar las barreras sociales, económicas, culturales e institucionales que limitan su ejercicio;

- el enfoque de articulación intersectorial e intergubernamental, que comprende la generación de mecanismos yespacios institucionalizados de coordinación y cooperación tanto vertical (intergubernamental) como horizontal (intersectorial) para la adecuada implementación de dicha política nacional; también se debe de implementar otros enfoques como el de género, intergeneracional, acción participante, la corresponsabilidad público-privada, interseccionalidad y territorial.

\subsection{Objetivos, ejes y lineamientos de la política nacional}

Conforme señala el numeral 3.3 de la Formulación de la Política Nacional de Lenguas Originarias, Tradición Oral e Interculturalidad, aprobada por Decreto Supremo N. 005-2017-MC, esta tiene como objetivo general garantizar los derechos lingüísticos de los hablantes de lenguas indígenas u originarias en el ámbito nacional, incorporando cambios y mejoras en el funcionamiento de la administración pública o en la prestación de los servicios públicos.

De la misma forma, esta norma señala como objetivos específicos que coadyuvan a garantizar los derechos lingüísticos de los hablantes de lenguas indígenas en el Perú, los siguientes: a) Garantizar la pertinencia lingüística en la prestación de servicios públicos y en el funcionamiento de las entidades del sector público; b) Fomentar la visibilización y el reconocimiento de las lenguas indígenas y la tradición oral en la sociedad peruana; c) Fortalecer las estrategias de prevención y los mecanismos de reacción contra los casos de discriminación por uso de lenguas indígenas u originarias; d) Fortalecer la identidad cultural y los procesos de transmisión de la lengua indígena y la tradición oral en los pueblos indígenas; e) Revitalizar y recuperar las lenguas indígenas u originarias, asegurando métodos participativos con énfasis en las lenguas más vulnerables; y f) Promover el desarrollo oral y escrito de las lenguas indígenas u originarias.

Finalmente, según la misma norma, se establecen tres ejes con sus respectivos lineamientos para la Política Nacional de Lenguas Originarias: 
1. EJE 1: Estatus de la lengua indígena u originaria, relacionado a los tres primeros objetivos específicos, cuyo lineamento general es generar la formación permanente, oportuna y de calidad de intérpretes y traductores de lenguas indígenas $u$ originarias a nivel nacional y generar información sobre los hablantes y la demanda de atención en lengua indígena u originaria en las entidades del sector público y las empresas que prestan servicios públicos.

2. EJE 2: Adquisición de la lengua indígena u originaria, relacionado al cuarto y quinto objetivo específico, teniendo como lineamiento general promover la transmisión intergeneracional, el aprendizaje, desarrollo de capacidades y procesos de recuperación.

3. EJE 3: Desarrollo de las lenguas indígenas u originarias, que tiene relación con el sexto objetivo específico, para la mejora y enriquecimiento de las lenguas.

\subsection{Acceso a la justicia y barreras lingüísticas}

Según Javier La Rosa Calle, el derecho a la justicia es el derecho de toda persona a tener un mecanismo eficaz que permita solucionar un conflicto de relevancia jurídica (LA ROSA, 2007, p.21). De ello se desprende que el derecho al acceso a la justicia implica el derecho de toda persona a obtener una respuesta satisfactoria a sus necesidades jurídicas, sin discriminación por razones de raza, sexo, edad, identidad, ideología política o creencia religiosa.

Por su parte Yuri Montesinos Álvarez, señala que el derecho de acceso a la justicia implica la posibilidad de toda persona, sin distinción de ningún tipo, de acceder a un mecanismo que le permita obtener una respuesta a un conflicto de relevancia jurídica (MONTESINOS ÁLVAREZ, 2012). Sin embargo, los alcances de este derecho pueden verse limitados o restringidos por diversos tipos de barreras, económicas, culturales, de género, o geográficas, siendo para nuestro estudio las denominadas barreras lingüísticas, es decir, las limitaciones al acceso a la justicia por el simple hecho de hablar un idioma distinto al castellano, constituyéndose en una traba para poder atender las demandas de solución de los conflictos de los hablantes de lenguas originarias.

En el Perú existen muchos casos o situaciones consideradas como barreras lingüísticas: a) Imposibilidad de los pueblos indígenas de poder utilizar sus lenguas ante el sistema de justica; b) Falta de funcionarios o personal del sistema de justica capacitados en lenguas originarias; c) Normas legales o estatales en castellano; y d) Predominancia de uso de medios escritos que contravienen a las lenguas originarias que son esencialmente orales. Estas cuatro limitaciones tienen su origen o causa en la falta de toma de conciencia de los gobernantes de turno sobre la existencia de una realidad multilingüe que existe en el Perú, sin que se tome en cuenta dicha realidad en todos los niveles de la organización del Estado peruano. 
En los últimos años, se han implementado algunas acciones destinadas a poder revertir estas limitaciones, como: a) La creación del juzgado intercultural de Paz Letrado del distrito de Víctor Fajardo; b) La emisión de las primeras sentencias en quechua y aimara en Puno; c) La decisión del ex Consejo Nacional de la Magistratura de otorgar puntajes en los procesos de selección de jueces a personas que tenga conocimiento de lenguas originarias; d) La capacitación de intérpretes por parte del Ministerio de Cultura; e) La institucionalización de las Mesas Regionales de Justicia Intercultural y las Escuelas Interculturales en varias Cortes Superiores; y f) La promulgación del Decreto Legislativo 1342, que promueve la transparencia y el derecho de acceso a la ciudadanía al contenido de las decisiones jurisdiccionales.

Sin perjuicio de estos avances, quedan tareas pendientes para eliminar las barreras lingüísticas, para poder garantizar el acceso a la justicia de la población indígena en su propio idioma, no solo mediante un mecanismo de atención a sus conflictos jurídicos, si no que permita la optimización de otros derechos fundamentales como el derecho a la igualdad, identidad o libre desarrollo de la personalidad. Además, para poder seguir trabajando en la eliminación de las barreas lingüísticas que subsisten, se debe promover un acceso real y efectivamente igualitario a la justicia para todos los miembros de los pueblos indígenas, y para ello es necesario tomar en cuenta algunas tareas pendientes: a) La implementación de la Política Nacional de Lenguas Originarias, Tradición Oral e Interculturalidad; b) Promover en los funcionarios públicos de las instituciones públicas locales, regionales y en los diferentes sectores, los alcances de la Ley de Lenguas Originarias, así como los alcances de nuevas normas como el Decreto Legislativo 1342; C) La difusión entre los propios hablantes de lenguas originarias los nuevos dispositivos que progresivamente se han venido promulgando; y d) El uso de plataformas como la televisión, la radio o el internet como aspectos complementarios de las exposiciones o capacitaciones en asambleas comunales, los cuales permitan transmitir contenidos con gran facilidad y sin limitarse al lenguaje escrito.

\section{Un nuevo modelo de Estado, justicia pluricultural y multilingüe}

La pluriculturalidad y el multilingüismo que caracterizan al Perú nos lleva a plantear un nuevo modelo de Estado y para ello se tiene que institucionalizar el multilingüismo en el sistema de justicia peruana, implementando las normas existentes, la eventual reforma de algunas normas no claras o insuficientes, el diseño de sistemas organizacionales, los recursos económicos, humanos y materiales, la difusión de derechos entre los usuarios de la justicia y una nueva cultura jurídica de los operadores jurídicos y de los propios usuarios.

Para poder institucionalizar una justicia multilingüe, deben existir ciertas condiciones básicas, entre ellas podernos señalar: 
a. El derecho de usar los idiomas indígenas a los sujetos procesales, se debe dar facilidades para una comunicación fluida en el propio idioma indígena, de lo contrario, sería viciado todo el proceso: cuando se trata de un procesado, inculpado o imputado se debe garantizar la presencia de un intérprete o mediante la justicia directa en idioma indígena. Este derecho está vinculado con otros derechos (derecho de defensa, debido proceso, igualdad de tarto ante los tribunales, acceso a la justicia, comunicación, derecho a ser oído, a declarar, a producir pruebas, a producir y controlar la prueba, a acceder a un recurso efectivo, a cuestionar una detención, interponer recursos, al principio del "juez natural" o derecho de ser juzgados por un juez que conoce el idioma, las costumbres y la cultura local). Cuando es agraviado o víctima, además de los derechos de procesado tiene derecho a la reparación. En el caso de los testigos, peritos o cualquier declarante se les debe permitir declarar en su idioma indígena como condición para garantizar la fidelidad de la declaración, lo que está vinculado con el debido proceso y permite cumplir con la finalidad de esclarecer los hechos y la responsabilidad penal. El público, cumple la función del control del proceso, en vista de que por los principios de la publicidad, imparcialidad y transparencia del proceso, el público debe tener acceso directo al debate público y poder comprender las declaraciones de las partes, lo que decide el órgano jurisdiccional, la acusación y la defensa.

b. El acceso a todas las dependencias del sistema de justicia (policiales, fiscalía, juzgados, penales) o a otras dependencias administrativas para recibir información, reclamos o presentar denuncias, demandas, quejas o responder ante ellas.

c. La práctica de la justicia bilingüe con intérpretes para casos cuando el declarante tiene dificultades comunicativas por ignorar o no comprender correctamente el idioma oficial en el que se desenvuelve el proceso, para una traducción o interpretación sistemática.

d. El acceso a la justicia directa en idiomas indígenas, supone que los jueces y operadores de justicia (policías, fiscales, abogados, etc.) no se valgan de terceros (intérpretes/traductores), sino que directamente se comuniquen con los sujetos procesales en su propio idioma indígena (YRIGOYEN FAJARDO, 2003. p. 91).

\section{Conclusiones y recomendaciones}

En el Perú actual, aún la cultura occidental domina diferentes ámbitos de la vida social y frente a ello, las demás culturas aparecen subordinadas. 
Como problemas públicos identificados, los hablantes de lenguas indígenas u originarias no pueden ejercer plenamente sus derechos lingüísticos, en vista de que la administración pública y los prestadores de servicios públicos funcionan bajo la lógica de un Estado monolingüe y monocultural. El desprestigio y desvaloración de las lenguas indígenas u originarias en la sociedad peruana, actos de discriminación por el uso de lengua indígena u originaria, el abandono de la lengua y otros elementos de identidad cultural en los pueblos indígenas u originarios así como el uso oral y escrito de las lenguas indígenas suele limitarse al ámbito doméstico y comunitario.

La importancia para los pueblos indígenas u originarios de acceder a la justicia en su propio idioma, radica en garantizar para ellos un mecanismo de atención a sus conflictos jurídicos, para permitir la optimización de los demás derechos fundamentales como el derecho a la igualdad, identidad o libre desarrollo de la personalidad.

Los derechos lingüísticos deben ser reconocidos como derechos fundamentales en su nivel individual y colectivo, en todos los espacios sociales en los que se desarrollan estas lenguas en la vida personal, social, ciudadana, educativa, política y profesional.

Existe la necesidad de seguir trabajando en la eliminación de las barreras lingüísticas existentes, promoviendo un acceso integral, efectivo y realmente igualitario a todo el sistema de justicia para todos los pueblos indígenas u originarios.

\section{Bibliografía}

ARDITO VEGA, W. (2009). Derechos Colectivos de los Pueblos Indígenas: El caso Peruano. Cuzco. CBC.

BERNABÉ VILLODRE, M. (2012). "Pluriculturalidad, Multiculturalidad e Interculturalidad. Aportaciones Arbitradas". Revista Educativa Hekademos. Nro. 11, Año $V$.

ENRIQUE HAMEL, R. (1995). "Derechos lingüísticos como Derechos Humanos: Debates y Perspectivas". Alteridades, Vol. 5. núm.10, México. Universidad Autónoma Metropolitana Unidad Iztapalapa.

LA ROSA CALLE, J. (2007)."Acceso a la Justicia: elementos para incorporar un enfoque integral de política pública". En LA ROSA, Javier (coordinador). Acceso a la justicia en el mundo rural. Instituto de Defensa Legal. Lima: IDL, Área de Acceso a la Justicia. 
MINISTERIO DE CULTURA (2016). Buenas Prácticas Interculturales en la Gestión Pública. Experiencias 2014-2015.

MONTESINOS ÁLVAREZ, Yuri. (2012). Diseño de políticas públicas sobre acceso a la información pública para minorías lingüísticas: aportes desde el derecho. Tesis de grado. PUCP.

MORENO GARCÍA, María Esther. (2010). “El Pluralismo como Necesidad en la Sociedad Actual". Revista Pedagogía Magna. 8, p. 120-126.

TRIBUNAL CONSTITUCIONAL DEL PERÚ (2007). Expediente 4719-2007-PHC/TC.

YRIGOYEN FAJARDO, R. (2001). Justicia y Multilingüismo. Pautas para alcanzar una Justicia Multilingüe en Guatemala. Programa de Justicia Checchi/AID.

YRIGOYEN FAJARDO, R. (2003). Fundamentos Jurídicos para una Justicia Multilingüe en Guatemala. Universidad Nacional Autónoma de México - Instituto de Investigaciones Jurídicas. 